\section{An infantile alantoaxial disloca- tion with patent foramen ovale managed with titanium cabling and allogenic bone grafts}

\author{
Seidu A. Richard,1-3 Zhi Gang Lan,1 \\ Xiao Yang, ${ }^{1}$ Siqing Huang1 \\ 1Department of Neurosurgery, West \\ China Hospital, Sichuan University, \\ Chengdu, China; 2Department of \\ Immunology, Jiangsu University, \\ Jiangsu, China; ${ }^{3}$ Department of \\ Surgery, Volta Regional Hospital, Ho, \\ Ghana
}

\begin{abstract}
Atlantoaxial dislocation is a disorder that is characterized with loss of stability of the atlas and axis (C1-C2) with consequential loss of usual articulation. Although this condition is very common, no one has reported a case as young as our patients. We present a 7-month infant with bilateral paralysis of the lower limbs for four (4) months with no history of trauma. Computer tomographic (CT-scan) imaging revealed alantoaxial dislocation with severe cervical spinal cord compression. The odontoid process is displaced outwardly with no bone destruction. Doppler echocardiogram done revealed patent foramen ovale. Thorough physical examination as well as radiological evaluation revealed no feather malformations. Electrophysiological studies reveal normal compound muscle action potentials (CMAP) and sensory nerve action potentials (SNAPs) in all the limbs. Electromyography (EMG) also revealed normal nerves in the limbs and the trunk. We attained a stable fusion and anatomical reduction using a posterior titanium wire and an iliac bone graft harvested from his mother. This is the youngest patient reported in literature. Infantile alantoaxial dislocation should be managed at early stage to prevent long-term neurologic disorders.
\end{abstract}

\section{Introduction}

Atlantoaxial dislocation is a disorder that is characterized with loss of stability of the atlas and axis $(\mathrm{C} 1-\mathrm{C} 2)$ with consequential loss of usual articulation.1-3 Functionally, the osseous articulations together with their enforcing ligaments essentially oppose forces in all directions of movement around the neck. ${ }^{1,4}$ Destabilize of the atlas and axis which usually constitutes a junction may arise as a result of diverse disease situations such as traumatic, inflammatory, idiopathic, or congenital abnormalities.1,2,4-8 This disorder can be substantially severe advancing disease with local pain, myelopathy or even death if the atlantoaxial instability is significate with no surgical intervention.1,3,8,9 Furthermore, subluxations may be asymptomatic or present with inexplicable neuronal signs and symptoms.1,4 Radiologically the distance between the anterior arch of the atlas and the odontoid is used in the diagnosis of atlantoaxial dislocation. This distance should not be greater than $3 \mathrm{~mm}$ in adults and $4.5 \mathrm{~mm}$ in children. ${ }^{1-3,6-9}$

In the management of patients with atlantoaxial dislocation, C1-C2 motion segment is precisely problematic.7,9,10 Many surgeons advocated an initial anterior decompression preceded with stable posterior craniocervical junction fixation and ventral neuronal compression. ${ }^{3,10}$ Also, to further decrease deformity, risk of potential neural damage as well as pain relief, posterior occipitocervical or atlantoaxial arthrodesis is recommended in patients with moderate to severe instability and in some instances asymptomatic patients. $1,6,10$ Furthermore, rigid stabilization, maintenance of alignment, minimal postoperative immobilization, and enhanced fusion rates are the key advantages of internal fixation. ${ }^{10}$ We present a case of congenital alantoaxial dislocation with patent foramen ovale managed with titanium cabling and allogenic bone grafts. To the best of our knowledge this is the youngest patient reported in literature and the first case with simultaneous occurrence of these two congenital disorders.

\section{Ethics approval and consent to participate}

The ethical committee of the hospital full approved our case study. The child's parents were informed about our intension to involve him in a case study and they agreed to partake in the study.

\section{Consent for publication}

The child's parents were dually informed about our intention to publish his case and they fully concerted to the use of these documents. The hospital also concerted to the use of this information for publication.

\section{Case Report}

We present a case of a 7-month infant
Correspondence: Siqing Huang, Department of Neurosurgery, Post Graduate Training Centre West China Hospital, Sichuan University, 37 Guo Xue Xiang Road, Chengdu, Sichuan, 610041, China.

Tel.: +86.18980601975 - Fax: +86.028.85422490.

E-mail: vipneurology@163.com

Key words: Atlantoaxial; dislocation; infantile; traumatic; inflammatory; congenital.

Contributions: SAR and ZGL conceived the project and designed the study. SAR, ZGL and XY collected patient's data. SH provided technical assistance in the study. SAR and ZGL prepared the illustrations. SAR, ZGL and XY analyzed data and SAR wrote the paper. All authors approved the paper for the submission.

Conflict of interests: the authors have no conflict of interest to disclose.

Received for publication: 31 July 2017 Revision received: 28 November 2017.

Accepted for publication: 28 November 2017

This work is licensed under a Creative Commons Attribution NonCommercial 4.0 License (CC BY-NC 4.0).

(C) Copyright S.A. Richard et al., 2018

Licensee PAGEPress, Italy

Pediatric Reports 2018; 10:7339

doi:10.4081/pr.2018.7339

with bilateral paralysis of the lower limbs for four (4) months. He was apparently doing well after birth until four months prior to presentation when the parents noticed that he could not move his neck freely and this progressed bilateral paralysis and severe irritability. He however had frequent upper repertory tract infection but no coughs. He did not have convulsions, feeding difficulties, painful micturition or passing stool. His parents denied history of any form of trauma during and after birth. Delivery was via spontaneous vagina delivery with no further instrumental assistance. His immunization was completed with his age.

On examination, we saw an infant who was warm to touch with a temperature of 38.8 degree Celsius and his neck in a cock robin posture. His head circumference was normal according to age with no abnormalities. Anterior and posterior fontanels were palpable but not bulging. Abdominal and chest examinations was unremarkable. Examination of the spine revealed tenderness at the cervical spine but no abnormities on thoracic and lumber spine. He however was not able to move his limbs. Further neurological examination did not yield 
much. The muscle bulk on all the limbs was normal with normal reflexes. Digital rectal examination revealed a normal spinster tone.

Laboratory investigations were normal but a Doppler echocardiogram done revealed patent foramen ovale. Computer tomographic (CT-scan) imaging revealed alantoaxial dislocation with severe cervical spinal cord compression. The odontoid process is displaced outwardly with no bone destruction. There is narrowing of the occipitocervical junction with a gross enlargement of distal cord (Figure 1A-D). $3 \mathrm{D}$ images also revealed a dislocation at the atlantoaxial joint (Figure 2). Electrophysiological studies reveal normal compound muscle action potentials (CMAP) and sensory nerve action potentials (SNAPs) in all the limbs. Electromyography (EMG) also revealed of normal nerves in the limbs and the truck. Thorough physical examination as well as radiological evaluation revealed no feather malformations. Based on the finding above, a working diagnosis of congenital atlantoaxial dislocation and patent foramen ovale with upper respiratory infection was made. After education and counselling of the patients, surgery was scheduled.

On the surgical table, we did not see any obvious abnormalities on skin around the neck (Figure 3A). After general anesthesia, the leads of the intraoperative neuromonitoring (IONM) which comprise of somatosensory evoked potentials (SSEPs) and motor evoked potentials (MEPs) were inserted into the appropriate muscles to monitor the never on the upper limbs as well as low cranial nerves. We found atlantoaxial joint dislocation outwardly and frontal as well as dislocation of the odontoid process backwardly. There was narrowing of the occipitocervical junction with a gross enlargement of distal cord. We attained a stable fusion and anatomical reduction using a posterior titanium wire and an iliac bone graft harvested from the patient's mother (Figure 3B-D). Postoperative MRI (Figure 4A and B) and $3 \mathrm{D}$ imaging (Figure $4 \mathrm{C}$ and $\mathrm{D}$ ) revealed a reduced atlantoaxial dislocation as well as titanium cabling and allogenic bone grafts in position. He was discharged from our ward ten (10) years after operation and scheduled cardiology outpatient follow-up arranged because of the patent foramen ovale. We also supported him with halo jacket for three months and he regained full motor function. Four (4) years follow-up revealed spontaneous closer of the patent foramen ovale and full motor function.

\section{Discussion}

Atlantoaxial dislocation is a disorder that is characterized with loss of stability of the atlas and axis $(\mathrm{C} 1-\mathrm{C} 2)$ with consequential loss of usual articulation. 1-3 Functionally, the osseous articulations together with their enforcing ligaments essentially oppose forces in all directions of

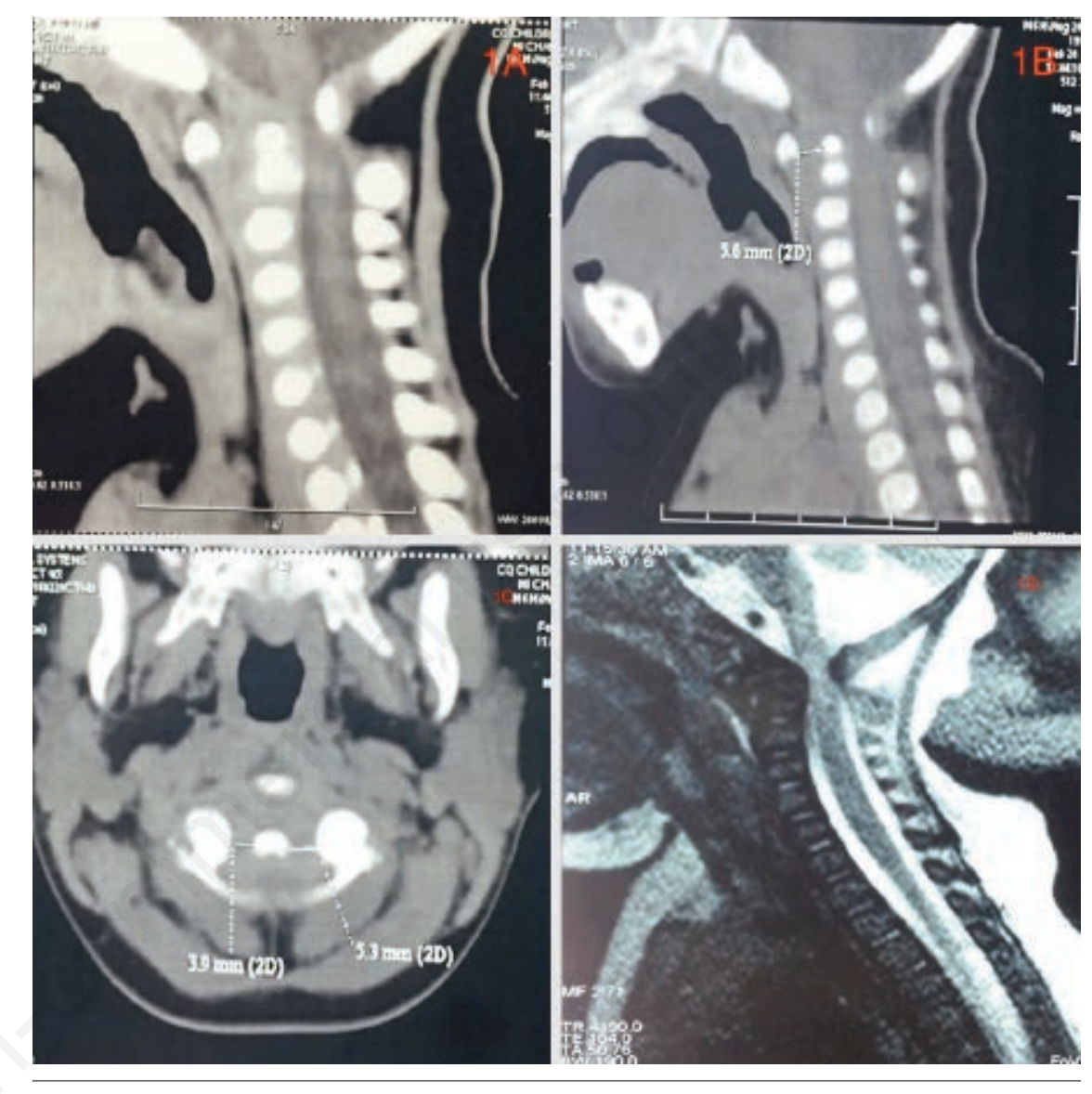

Figure 1. A-D) Are MRI showing the atlantoaxial dislocation with severe cervical spinal cord compression.
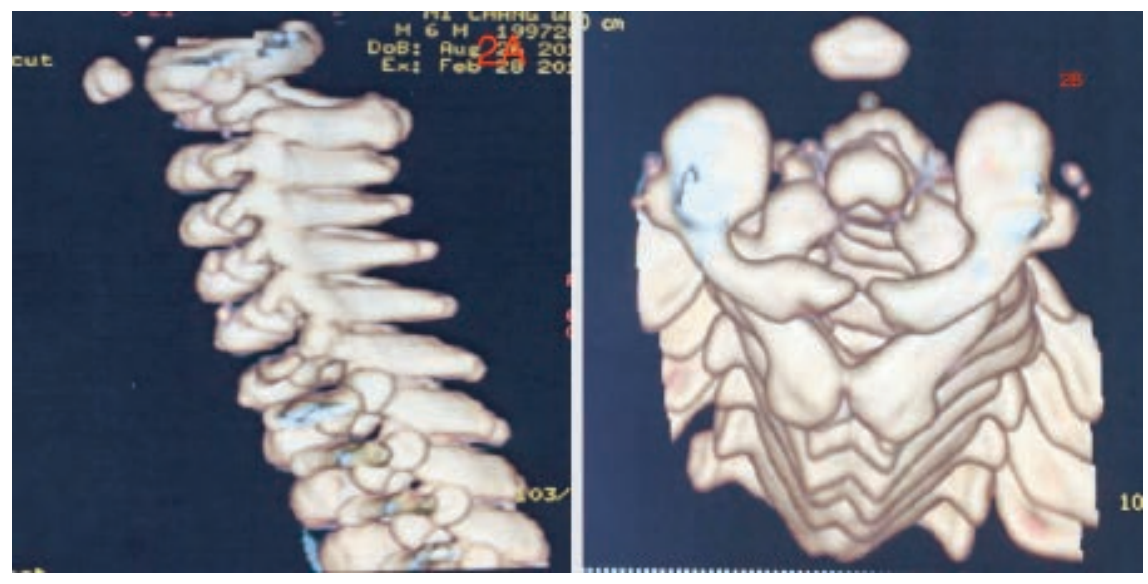

Figure 2. A-B) Are 3D images showing the atlantoaxial dislocation. movement around the neck. ${ }^{1,4}$ Although this disorder can present at any age, it has not been seen in infants in literature. It is often seen in adolescents and occasional children. 1,3,9 To the best of our knowledge this is the youngest patient reported in literature and the first case with simultaneous occurrence of these two congenital disorders. The mechanism of injury is still a matter of debate since no author has clearly 
explained the pathological process involved in literature. ${ }^{1}$ Many authors are of the view that the cause of atlantoaxial dislocation is generally multifactorial and can be broadly categorized into traumatic, congenital, or inflammatory etiologies. ${ }^{1-8}$

Traumatic atlantoaxial dislocation occurs when a force dislodges the neck from its original subluxation state leading to destruction of the transverse ligament.1,11 Occasionally, there is concomitant interruption of the alar and apical ligaments as a result of injury of the transverse ligament. ${ }^{1,11}$ The atlas may lose articulation with the dens, and the anterior atlantal arch may transmute totally superiorly and posteriorly with substantial destruction to the ligaments during these traumatic dislocations. ${ }^{11-13}$ A number of congenital disorders have been linked to the development of craniocervical area distortions which predispose affected individuals to atlantoaxial dislocation.1,14 Down syndrome (trisomy 21 ) is one of the congenital chromosomal syndrome is well known to be associated with atlantoaxial dislocation.1,15 Hypermobility and instability as a result of ligamentous laxity and osseous deformities are the predisposing ramification of atlantoaxial dislocation occurring as result of downs syndrome in about $15-20 \%$ of cases.1,16-18 Another congenital syndrome associated with atlantoaxial dislocation is spondyloepiphyseal dysplasia which comprises of numerous conditions and usually marked with anomalous development of the spinal vertebrae and epiphysis. ${ }^{1}$ Short-trunk dwarfism, short proximal and middle limbs with however normal-sized hands and feet are cardinal signs seen in patients with spondyloepiphyseal dysplasia. ${ }^{1,15}$ Furthermore, skeletal dysplasias are also a heterogeneous group of syndromes that are marked with anomalous cartilage and bone formation, growth as well as remodeling. Some of the conjoint spinal hitches that are associated with skeletal dysplasias are craniocervical junction anomalies, atlantoaxial dislocation, and kyphoscoliotic abnormalities. 1,15 Goldenhar syndrome is another heterogeneous condition marked with spinal anomalies, hemifacial microsomia, and epibulbar dermoid appendages. Hypoplasia of the dens with atlantoaxial instability has been seen in children with this syndrome. 1,15 The inflammatory condition that is commonly associated with atlantoaxial dislocation is chronic rheumatoid arthritis which mostly seen adult's patients. The incidence rates chronic rheumatoid arthritis advancing to atlantoaxial dislocation is about $23-86 \%$ and the atlantoaxial joint rheumatoid arthritis is usually the origin. ${ }^{1,19-21}$
Embryonically, the first and second cervical vertebrae have a distinct formation. The atlas or $\mathrm{C} 1$ is characterized with three primary ossification sites during it formation and these are, the anterior arch and the two neural arches which enclose the anterior arch and join as life advances to form the posterior arch. ${ }^{4}$ The neural arches emerge during the $7^{\text {th }}$ week of fetal life but the anterior arch ossifies at birth and seen as an ossification complex during the first year in about $20 \%$ of children. In many instances nonfusion the anterior arch with the neural arches may be mistaken for a fracture before age seven.4,22,23 Furthermore, during the 3 year of life the neural arches fuse posteriorly but sporadically, the anterior ossification center of $\mathrm{C} 1$ is not formed and the neural arches try to fuse anteriorly leading to a fusion anomaly. This anomaly can be distinguished from a fracture because it displays sclerotic margins. ${ }^{4}$

The axis (C2), has the most multifarious and distinct formation pattern among all the vertebrae. ${ }^{4}$ It comprises of four ossification centers when the child is born, usually one for each neural arch, one for the body, and one for the odontoid process. The odontoid process often develops in utero during the 7th fetal month from two separate ossification centers that fuse in the midline. ${ }^{4}$ Furthermore, between 3 and 6 (years) as the child advances with age, a secondary ossification center appears at the apex of the odontoid process (os terminale) and fuses by age 12 (years). ${ }^{4}$ It is however important to note that the body of $\mathrm{C} 2$ fuses with the odontoid process between age three and six. This fusion line also referred to as subdental synchondrosis, or the remnant of the cartilaginous synchondrosis is usually visible up to age 11 (years) and may be mistaken for a fracture. The neural arches fuse posteriorly between the ages of 2 and 3 (years) and with the body of the odontoid process between 3 and 6 years of age. $4,22,23$

The manifestations of atlantoaxial dislocation may vary from slight axial neck pain to very severe debilitating illness and finally death. Nearly $50 \%$ of cases are seen
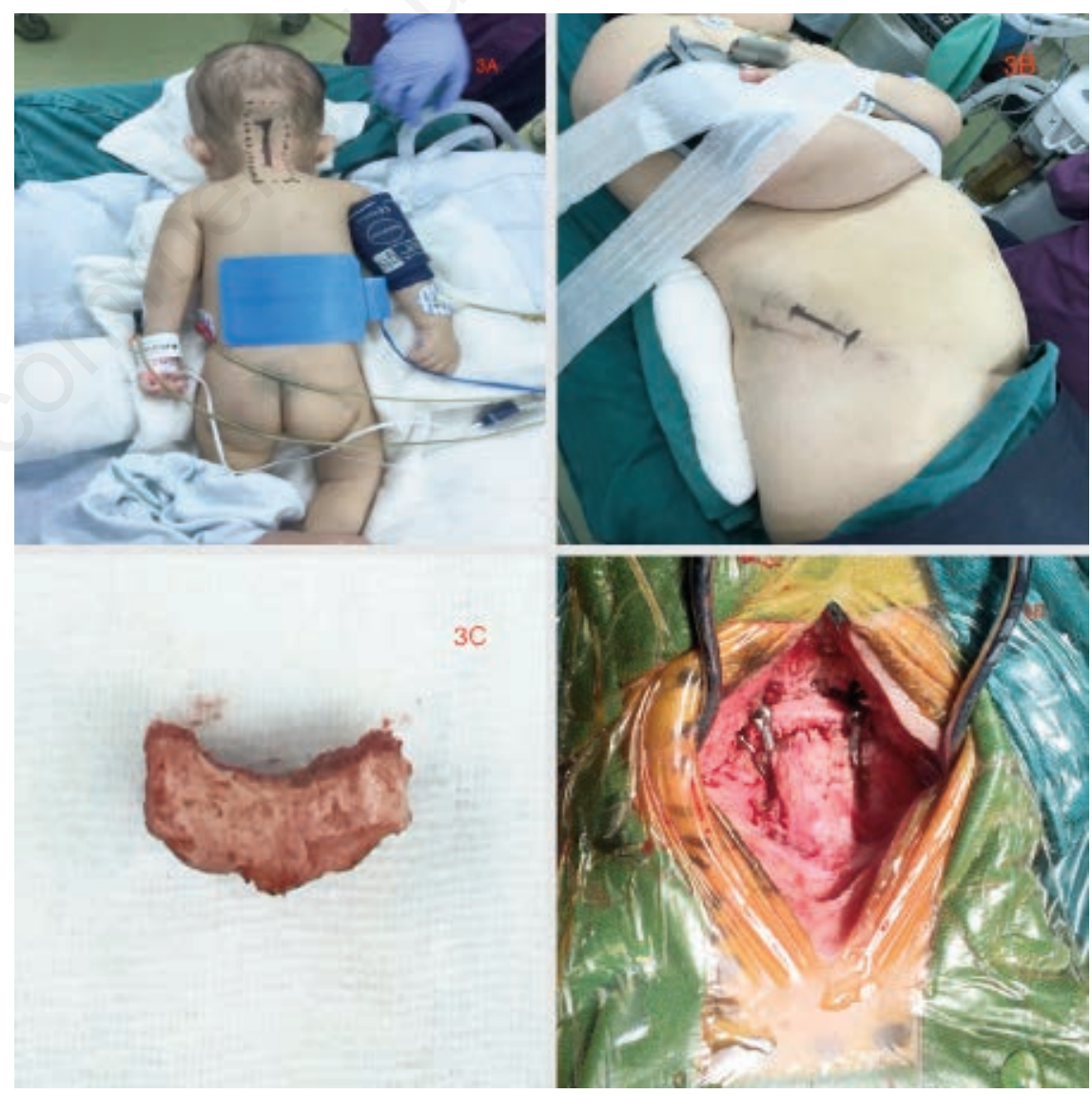

Figure 3. A) Showing child on the surgical table with a marking of the incision site; B) showing the patient's mother prepped for iliac bone graft harvest; $C$ ) showing the harvested bone graft with a slight curvature in the middle; and D) showing intraoperative C1-C2 fusion with the bone graft fixed by titanium wires. 
with neck pain and/or neck movement restriction while $70 \%$ with weakness and/or numbness, and $90 \%$ with pyramidal signs. ${ }^{1,24-26}$ Low sphincter tone and lower cranial nerve dysfunction have also been reported as the signs and symptoms of this disorder. ${ }^{1}$ Furthermore, severe clinical manifestations such as myelopathy, respiratory distress or respiratory failure, vertebral artery dissection, neurologic compromise, and rarely quadriplegia or death if left untreated have also been reported.1,27-31 Atlantoaxial dislocation should be suspected in a child who get irritated or reluctant turning their head when signs and symptoms do not match with the diagnosis of torticollis.1,32 The clinical manifestation of atlantoaxial dislocation in adults has generally been due to rheumatoid arthritis, with varying symptoms such as instability and neurologic compromise. Torticollis, atlantoaxial rotary fixation, and odontoid fractures without atlantoaxial dislocation should usually be ruled out during the evaluation of patients with atlantoaxial dislocation. 1

The distance between the anterior arch of the atlas and the odontoid is the most crucial radiological feature used to diagnose atlantoaxial dislocation. The presentation is very suggestive when this distance is greater than $3 \mathrm{~mm}$ in adults and $4.5 \mathrm{~mm}$ in children.1-3,6-9 Furthermore, the distance between the postero-inferior rim of the anterior arch of atlas and the residual segment of the odontoid or the anterior superior edge of the body of axis should be suggestive in cases with hypoplastic odontoid. ${ }^{9}$ Plain radiographs of the craniovertebral junction usually showing translateral views in neutral position, flexion and extension are advantageous in arriving at preliminary conclusion of atlantoaxial dislocation. ${ }^{9}$ This usually serve as a reference for the successive ongoing evaluation of the degree of disruption and the alteration in curvature on the application of a traction; and, can be associated with the postoperative plain radiographs in deciding the appropriateness of posterior stabilization and bony union. ${ }^{9}$

Multiplanar evaluation with inflexion and extension using intrathecal contrast CT scan with axial, sagittal, coronal views as well as three-dimensional reconstructions is usually recommended for a three-dimensional evaluation of the bony configuration of the craniovertebral junction. ${ }^{9}$ This is beneficial during the evaluating because it's able to determine the degree of cervicomedullary compression, presence of Chiari malformation as well as appropriate delineation of bony anomalies. ${ }^{9}$ Furthermore, a preoperative MRI aids in the evaluation of soft tissue abnormalities such as syringomyelia and the degree of cervicomedullary compression as well as cord vicissitudes. However, an MRI at follow-up is recommended in situation in which titanium implants are used but not possible in cases where metallic wires or rods used as implants for posterior stabilization. ${ }^{9}$ This makes our treatment option more appropriate because we can follow-up our case with MRI. ${ }^{9}$

Greenberg is one of the early clinicians who first proposed a classification system for atlantoaxial dislocation. He subcategorized this dislocation into reducible and irreducible and proposed management approach to this subcategorise. $1,33 \mathrm{He}$ precisely specified that the management of irreducible atlantoaxial dislocation should be focused on immediate decompression as well as stabilization.1,33 Fielding and Hawkins later come out with a new classification system which focuses on the direction of dislocation that is anterior, posterior, lateral, and rotational but their classification has setbacks.1,34 Wang et al. classification system is most recent and novel because it gives a distinctive diagnosis and management decorum for patients with atlantoaxial dislocation. 1,35 The management algorithm proposed by Wang et al. which comprises of preoperative assessment using dynamic radiographs, reconstructive $\mathrm{CT}$, and skeletal traction test. This classification therefore categorizes atlantoaxial dislocation into four types which includes, instability as type I, reducible dislocation as type II, irre-
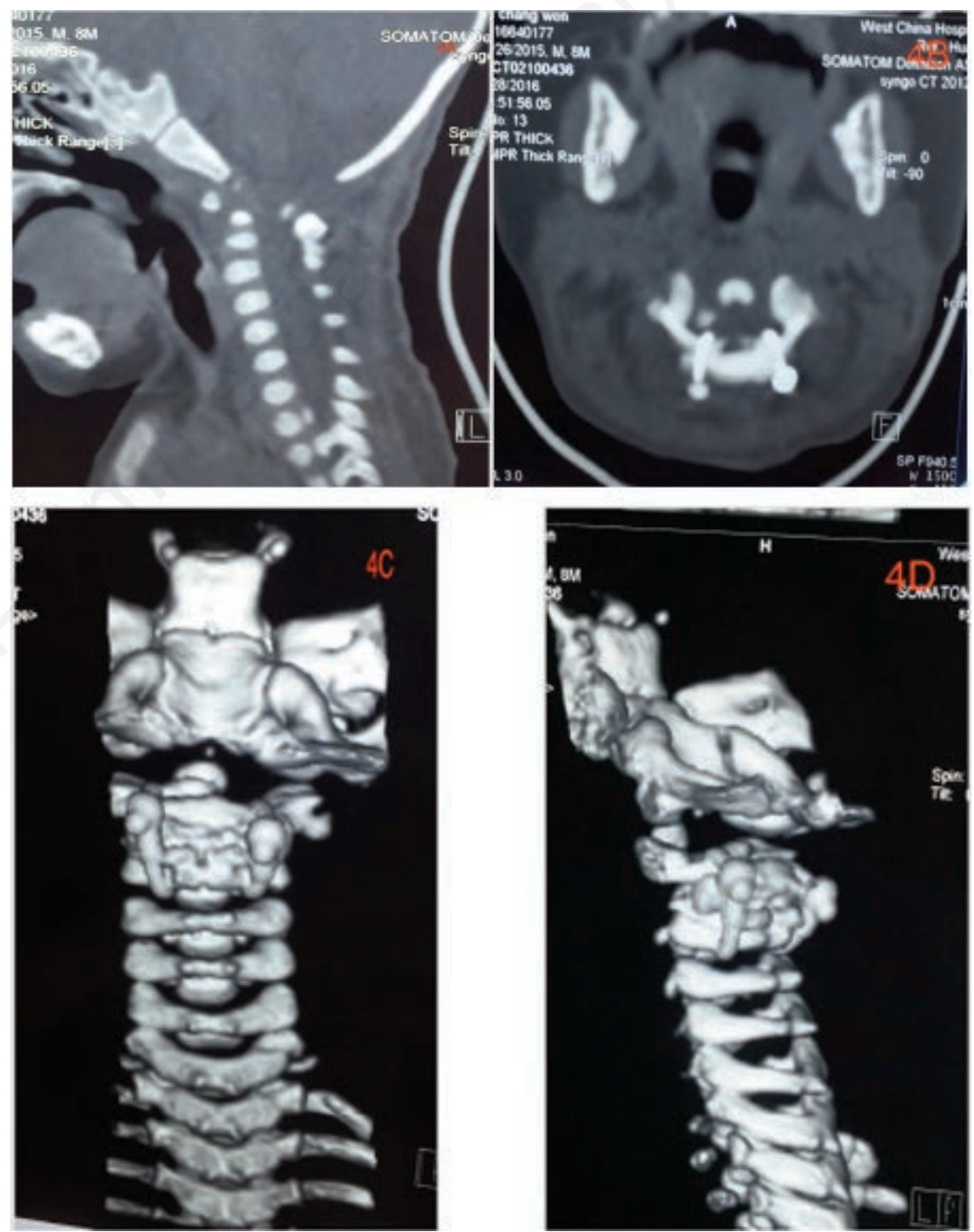

Figure 4. A-B) Are postoperative MRI showing good anatomical reduction; while C-D) are $3 \mathrm{D}$ postoperative images also showing good anatomical reduction. 
ducible dislocation as type III, and bony dislocations as type IV.1,35

The general purpose of managing atlantoaxial dislocation is to rectify the sagittal structure of the upper cervical spine and the stabilization that is close to normal anatomical configuration. 1,8,36 Up to data, there is still no homogeneously recognized technique or management approaches to atlantoaxial dislocation. Therefore, we still have colossally anecdotal views on indications of nonoperative versus operative management options as well as which operative techniques are most suitable. $1,8,18,37-41$

Nonoperative management of atlantoaxial dislocation comprises of the application of a cervical halter traction in the supine position and active range-ofmotion exercises for 24 to 48 hours first, preceded with ambulatory orthotic immobilization with active range-of-motion maneuvers until free movement returns. ${ }^{1,42}$ Nonoperative treatment modality is recommended for children presenting acutely with evidence of transverse ligament disorder with no neurologic injury, diagnosed within 3 weeks.1,43 This treatment option is also advocated for preventative treatment and screening as well. Preventative treatment and screening options is usually advocated in patients with Down syndrome. ${ }^{1}$

As part of their routine evaluation, serial cervical radiographs are done between 3 and 5 years of age and have their cervical canal width measured.1,44 The ideal treatment modality for a subset of patients with Down syndrome with associated asymptomatic atlantoaxial dislocation is still a matter of debate. ${ }^{1,45}$ Furthermore, cervical flexion-extension films every 6 months without contact sports is advocated in patients with Goldenhar syndrome with an atlantodental interval less than $6 \mathrm{~mm}$. However, in any child with instability greater than $6 \mathrm{~mm}$, surgical treatment is advocated to decrease the likelihood of disastrous spinal cord impingement. Moreover, patients with Goldenhar syndrome may necessitate extensive radiographic evaluation and planning before surgery due to the excessive incidence of cervical malformations. ${ }^{1,46}$

Some authors advice that attempts should be made at conversion of irreducible atlantoaxial dislocation to reducible via Traction. $1,8,34,41$ Diverse intraoperative or preoperative modalities should be exploited to achieve reduction via traction when the dislocation is not effortlessly reducible by neck flexion or extension. ${ }^{1}$ Traction stretches and slackens muscles across the dislocation, thus allowing resolving of structures into normal anatomical position. Furthermore, some authors advocate curarization of back and neck muscles to relieve tension before applying skeletal traction under general anesthesia. This allows for a rapid reduction before fixation in the same surgical operation. 1,8,18,41 The perfect reduction technique of curarization last about 10 minutes with an initial traction weight of $7-8 \%$ of total body weight and progressively adjusted to a maximum of about $7 \mathrm{~kg}$. However, reduction ought to be monitored with serial lateral radiographs. 1,8,37,47

Anterior surgical approach is advised in patients with irreducible dislocation with progressive cord compression leading to profound neurologic deficit after traction. $1,8,35$ We advocate that intraoperative electrophysiological studies such as compound muscle action potentials (CMAP) and sensory nerve action potentials (SNAPs) be monitored. Electromyography (EMG) should also be applied to monitor nerves in the limbs and the trunk. ${ }^{48}$ Intraoperatively, some authors advocate that irreducible atlantoaxial dislocation be decompressed prior to fixation although it is proven that neurologic status can improve with only effective fusion. Transoral odontoidectomy is now, the most recognized treatment modality for irreducible atlantoaxial dislocation although other anteriorly approaches like transoral anterior release and transoral atlantoaxial reduction plate (TARP), have also proven to be effective. ${ }^{1,8,49}$ Anterior transarticular screw fixation another anterior approach used to reduce fixed atlantoaxial dislocation. This approach offers a securer and extra suitable milieu with high fusion rates and negligible hitches for difficult cases like in patients with osteolysis in infectious or tumorous disorders, aberrant vertebral artery, and/or narrow pars interarticularis. ${ }^{1,8,50}$ However, safe screw dimension, insertion, and trajectory are the major short comings with the approach. ${ }^{1}$

The TARP is advantageous because it avoids the usual two-step operation. This technique utilizes a reduction plate that efficiently aid in anterior decompression, reduction, and fusion for anterior irreducible atlantoaxial dislocation in one operation. ${ }^{1,8,51-53}$ In this technique, incision of the posterior pharynx and exposure of $\mathrm{C} 1$ and $\mathrm{C} 2$ are totally analogous to the other transoral approaches. The TARP is inserted at anterior portion of $\mathrm{C} 1$ while the reduction screw is then implanted into the $\mathrm{C} 2$ body. One notch of the TARP system secures the TARP at the midline and the other secures the protruding reduction screw, initiating interference between $\mathrm{C} 1$ and $\mathrm{C} 2$ resulting shifting of $\mathrm{C} 1$ superiorly with the reduction screw as a base. The joint is then fused with bone graft. $1,8,51,52$ In the transoral odon- toidectomy however, the apical and alar ligaments are separated with a curette followed by amputation of the dens from top down. 1,8,49 Furthermore, odontoidectomy endoscopically through a transnasal, transoral, or retropharyngeal approach is the now the treatment option adapted by most surgeons. The endoscopic transoral odontoidectomy system gains access vie an incision in the midline pharyngeal wall, circumventing any palatal piercing or use of selfretaining retractors. This approach has so far gained recognition because it improves neurologic status after surgery.1,8,54 However, cerebrospinal fluid leakage, inadequate decompression, infection, abscess formation, vertebral artery injury, and spinal cord injury have been re-counted with transoral decompression. 1,8,40,49,55,56

$\mathrm{C} 1-\mathrm{C} 2$ transarticular screw fixation, $\mathrm{C} 1$ lateral mass screw-to- $\mathrm{C} 2$ pedicle screw fixation, and $\mathrm{C} 1$ lateral mass screw-to-C2 laminar screw fixation are the most recognized posterior surgical approaches used in reducing atlantoaxial dislocation.1,8 Posterior approaches are either use alone or in combination with anterior transoral decompression to manage certain kinds of irreducible atlantoaxial dislocation.1,8 Gallie or Brooks technique of wiring and bone grafting to fuse and stabilize the atlantoaxial joint is original surgical managements for atlantoaxial dislocation. 1,8,57 This technique is rare used because posterior wiring involves external immobilization (bracing) of the head and neck postoperatively and lengthier stay in the hospital with a nonunion rate of about 30\%.1,8,58-61

Magerl in 1986 described a much more better technique which involves $\mathrm{C} 1-\mathrm{C} 2$ transarticular screw fixation with posterior wiring. This technique was widely accepted as the gold standard treatment of atlantoaxial dislocation because of its superior biomechanical strength and high fusion rates as compared to posterior wiring. 1,8,61 Furthermore, the fusion rate of this technique is as high as $100 \%$. $^{1,8,62-64}$ This technique is effective because it offers instant and direct fixation at the atlantoaxial joint. Intraoperatively, a midline incision is made to expose the posterior arch of $\mathrm{C} 1$ and lamina of $\mathrm{C} 2$ followed by the screw which positioned anteriorly through the $\mathrm{C} 2$ pars, across the $\mathrm{C} 1-\mathrm{C} 2$ joint, and into the anterior aspect of the lateral mass of the atlas. 1,8,62,63

In 1995, McGuire and Harkey presented a modification of Magerl technique to curtail tissue dissection in which a negligible midline incision is accompanied with two bilateral 1-cmcaudal percutaneous incisions of about $2 \mathrm{~cm}$ lateral to the $\mathrm{T} 1$ spinous process. 1,8,62,65,66 Furthermore, another modified Magerl technique that utilizes 
transarticular screw fixation with morselized autograft without posterior wiring has been described.1,39 This technique has less biomechanical strength as compare to the Magerl technique. Additionally, patients well-maintained a high fusion rate and the risk of neurologic hitches as well as slackening of cables associated with posterior wiring. 1,39 The $\mathrm{C} 1$ lateral mass screw and $\mathrm{C} 2$ pedicle screw fixation (C1LC2PSF) utilizes a C1 lateral mass screw technique in combination with a $\mathrm{C} 2$ pedicle screw fixation connected by rods to stabilize the atlantoaxial joint, though certain hospitals favor plates connecting the fixation points. $1,60,67,68$ The technique allows for extension to the occiput or subaxially if necessary, and screw positioning is more accurate. ${ }^{1,69,70}$ Moreover, it permits intraoperative reduction after screw fixation. 1,60

Yeom and colleagues compared the risk of vertebral artery injury in $\mathrm{C} 1-\mathrm{C} 2$ transarticular screw versus $\mathrm{C} 2$ pedicle screw and discovered that the two methods did not vary in risk of vertebral artery injury so they suggested the use of pedicle screw over transarticular screw in cases of high riding vertebral artery. 1,8,32 Moreover, the $\mathrm{C} 1$ lateral mass screw and $\mathrm{C} 2$ laminar screw fixation (C1L-C2LSF) method was explained in 2004 and it involves the use of a crossed screw method across the $\mathrm{C} 2$ lamina. This technique curtails the risk of vertebral artery injury as compared to transarticular screw fixation and C1L-C2PSF. It also permits direct visualization of the lamina to guide screw positioning intraoperatively. $1,8,11,26,45$

\section{Conclusions}

This is the youngest patient reported in literature. Atlantoaxial dislocation should be suspected in an infant who gets irritable when the caregivers try to move his or her neck. The cause of atlantoaxial dislocation is generally multifactorial and can be broadly categorized into separate traumatic, congenital, or inflammatory etiologies. The gold standard diagnostic modality for atlantoaxial dislocation is radiology. Infantile alantoaxial dislocation should be managed at early stage to prevent long-term neurologic disorders. Although so many surgical techniques have been described in literature, no one surgical approach has been singled out as best. We are therefore of the view that surgery approaches should be the surgeon's choice but must have limited complications.

\section{References}

1. Yang SY, Boniello AJ, Poorman CE, et al. A review of the diagnosis and treatment of atlantoaxial dislocations. Global Spine J 2014;4:197-210.

2. Sinh G. Congenital atlanto-axial dislocation. Neurosurg Rev 1983;6:211-20.

3. Salunke P, Sharma M, Sodhi HBS, et al. Congenital atlantoaxial dislocation: a dynamic process and role of facets in irreducibility. J Neurosurg Spine 2011; 15: 678-85.

4. Lustrin ES, Karakas SP, Ortiz AO, et al. Pediatric cervical spine: normal anatomy, variants, and trauma. Radiographics 2003;23:539-60.

5. Bhagwati S, Deopujari C, Parulekar G. Trauma in congenital atlanto-axial dislocation. Childs Nerv Syst 1998;14: 719-21.

6. Rao B, Taraknath V, Sista V. Congenital atlanto axial dislocation. Ann Acad Med Singapore 1993;22:847-51.

7. Kumar R, Nayak SR. Management of pediatric congenital atlantoaxial dislocation: a report of 23 cases from northern India. Pediatr Neurosurg 2002;36: 197-208.

8. Yin Qs, Wang Jh. Current trends in management of atlantoaxial dislocation. Orthopaed Surg 2015;7:189-99.

9. Jain V, Behari S. Management of congenital atlanto-axial dislocation: Some lessons learnt. Neurol India 2002;50: 386-97.

10. Dasari R, Prasad KS, Sandeep B, Raman B. Case series of clinical study and surgical management of atlanto axial dislocation our institute experience. Int J Res Med Sci 2017;5:123040.

11. Venkatesan M, Bhatt R, Newey $M$. Traumatic atlantoaxial rotatory subluxation (TAARS) in adults: a report of two cases and literature review. Injury 2012;43:1212-5.

12. Wong DA, Mack RP, Craigmile TK. Traumatic atlantoaxial dislocation without fracture of the odontoid. Spine 1991;16:587-9.

13. Grauer JN, Shafi B, Hilibrand AS, et al. Proposal of a modified, treatment-oriented classification of odontoid fractures. Spine J 2005;5:123-9.

14. Menezes AH, VanGilder JC, Graf CJ, McDonnell DE. Craniocervical abnormalities: a comprehensive surgical approach. J Neurosurg 1980;53:444-55.

15. Song D, Maher CO. Spinal disorders associated with skeletal dysplasias and syndromes. Neurosurg Clin North Am 2007;18:499-514.
16. Curtis BH, Blank S, Fisher RL. Atlantoaxial dislocation in Down's syndrome: report of two patients requiring surgical correction. JAMA 1968;205:464-5.

17. Martel W, Tishler JM. Observations on the spine in mongoloidism. Am J Roentgenol 1966;97:630-8.

18. Hedequist D, Bekelis K, Emans J, Proctor MR. Single stage reduction and stabilization of basilar invagination after failed prior fusion surgery in children with Down's syndrome. Spine 2010;35:E128-33.

19. Bouchaud-Chabot A, Lioté F. Cervical spine involvement in rheumatoid arthritis. A review. Joint Bone Spine 2002;69:141-54

20. Neva MH, Kaarela K, Kauppi M. Prevalence of radiological changes in the cervical spine-a cross sectional study after 20 years from presentation of rheumatoid arthritis. J Rheumatol 2000;27:90-3.

21. Pellicci P, Ranawat CS, Tsairis P, Bryan WJ. A prospective study of the progression of rheumatoid arthritis of the cervical spine. JBJS 1981;63:342-50.

22. Herman MJ, Pizzutillo PD. Cervical spine disorders in children. Orthop Clin North Am 1999;30:457-66.

23. Ogden J. Radiology of postnatal skeletal development. XI. The first cervical vertebra. Skeletal Radiol 1984;12:1220.

24. Passias PG, Wang S, Kozanek M, et al. Relationship between the alignment of the occipitoaxial and subaxial cervical spine in patients with congenital atlantoxial dislocations. Clin Spine Surg 2013;26:15-21.

25. Yin $Y H$, Qiao GY, Yu XG, et al. Posterior realignment of irreducible atlantoaxial dislocation with $\mathrm{C} 1-\mathrm{C} 2$ screw and rod system: a technique of direct reduction and fixation. Spine $J$ 2013; 13:1864-71

26. Sobolewski BA, Mittiga MR, Reed JL. Atlantoaxial rotary subluxation after minor trauma. Pediatr Emerg Care 2008;24:852-6.

27. Wadia N. Myelopathy complicating congenital atlanto-axial dislocation. Brain 1967;90:449-80.

28. Panda S, Ravishankar S, Nagaraja D. Bilateral vertebral artery dissection caused by atlantoaxial dislocation. J Assoc Physicians India 2010;58:187-9.

29. Reddy KRM, Rao GSU, Devi BI, et al. Pulmonary function after surgery for congenital atlantoaxial dislocation: a comparison with surgery for compressive cervical myelopathy and craniotomy. J Neurosurg Anesthesiol 2009;21:196-201. 
30. Lan ZG, Richard SA, Liu J, You C. Chiari type I malformation with cervicothoracic syringomyelia subterfuge as flail arm syndrome. Neurol Int 2017; 9:7336.

31. Lan ZG, Richard SA, Lei C, Ju Y. Thoracolumbar Langerhans cell histiocytosis in a toddler. J Pediatr Surg Case Rep 2017 [In Press].

32. Yeom JS, Buchowski JM, Kim HJ, et al. Risk of vertebral artery injury: comparison between $\mathrm{C} 1-\mathrm{C} 2$ transarticular and C2 pedicle screws. Spine J 2013;13: 775-85.

33. Greenberg AD. Atlanto-axial dislocations. Brain 1968;91:655-84.

34. Fielding JW, Hawkins R. Atlanto-axial rotatory fixation. Fixed rotatory subluxation of the atlanto-axial joint. JBJS 1977;59:37-44

35. Wang S, Wang C, Yan M, et al. Novel surgical classification and treatment strategy for atlantoaxial dislocations. Spine 2013;38:E1348-56.

36. Fielding J, Hawkins R, Ratzan S. Spine fusion for atlanto-axial instability. JBJS 1976;58:400-7.

37. Salunke P, Behari S, Kirankumar MV, et al. Pediatric congenital atlantoaxial dislocation: differences between the irreducible and reducible varieties. J Neurosurg Pediatr. 2006;104:115-22.

38. Nordt JC, Stauffer ES. Sequelae of atlantoaxial stabilization in two patients with Down's syndrome. Spine 1980; 6:437-40.

39. Wang C, Yan $M$, Zhou $H$, et al. Atlantoaxial transarticular screw fixation with morselized autograft and without additional internal fixation: technical description and report of 57 cases. Spine 2007;32:643-6.

40. Wang C, Yan M, Zhou HT, et al. Open reduction of irreducible atlantoaxial dislocation by transoral anterior atlantoaxial release and posterior internal fixation. Spine 2006;31:E306-13.

41. Zhang $\mathrm{K}, \mathrm{Xu} \mathrm{J}$, Wang Q, et al. Treatment of dens fractures with posterior atlantoaxial dislocation with transoral atlantoaxial reduction plate surgery: case report and introduction of a novel treatment option. Spine 2012;37:E4515.

42. Egol KA, Koval KJ, Zuckerman JD. Handbook of fractures. Philadelphia: Lippincott Williams \& Wilkins; 2010.

43. Chechik O, Wientroub S, Danino B, et al. Successful conservative treatment for neglected rotatory atlantoaxial dislocation. J Pediatr Orthop 2013;33:38992.
44. Cohen WI. Current dilemmas in Down syndrome clinical care: Celiac disease, thyroid disorders, and atlantoaxial instability. Paper presented at: American Journal of Medical Genetics Part C: Seminars in Medical Genetics 2006.

45. Pueschel SM, Scola FH. Atlantoaxial instability in individuals with Down syndrome: epidemiologic, radiographic, and clinical studies. Pediatrics 1987; 80:555-60.

46. Healey D, Letts M, Jarvis JG. Cervical spine instability in children with Goldenhar's syndrome. Canad J Surgery 2002;45:341.

47. Behari S, Bhargava V, Nayak S, et al. Congenital reducible atlantoaxial dislocation: Classification and surgical considerations. Acta Nurochir 2002;144 :1165-77.

48. Richard SA, Lan ZG, Zhang Y, You C. Accessory nerve schwannoma extending to the foramen magnum and mimicking glossopharyngeal nerve tumor: a case and review of surgical techniques. World J Neurosci 2017;7:233-43.

49. Mummaneni PV, Haid RW. Transoral odontoidectomy. Neurosurgery 2005; 56:1045-50.

50. Padua MR, Yeom JS, Lee SY, et al. Fluoroscopically guided anterior atlantoaxial transarticular screws: a feasibility and trajectory study using CTbased simulation software. Spine J 2013;13:1455-63.

51. Yin Q, Ai F, Zhang K, et al. Irreducible anterior atlantoaxial dislocation: onestage treatment with a transoral atlantoaxial reduction plate fixation and fusion. Report of 5 cases and review of the literature. Spine 2005;30:E375-81.

52. Yin Qs, Ai Fz, Zhang K, et al. Transoral atlantoaxial reduction plate internal fixation for the treatment of irreducible atlantoaxial dislocation: a 2 to 4-year follow-up. Orthop Surg 2010;2:149-55.

53. Wang MY. C2 crossing laminar screws: cadaveric morphometric analysis. Operative Neurosurg 2006;59:84-8.

54. Yadav Y, Shenoy R, Mukerji G, et al. Endoscopic transoral excision of odontoid process in irreducible atlanto-axial dislocation. Progr Clin Neurosci 2010;24.

55. Subin B, Liu JF, Marshall GJ, et al. Transoral anterior decompression and fusion of chronic irreducible atlantoaxial dislocation with spinal cord compression. Spine 1995;20:1233-40.

56. Jain V, Behari S, Banerji D, et al. Transoral decompression for craniover- tebral osseous anomalies: perioperative management dilemmas. Neurol India 1999;47:188.

57. Brooks AL, Jenkins E. Atlanto-axial arthrodesis by the wedge compression method. JBJS 1978;60:279-84.

58. Cassinelli EH, Lee M, Skalak A, et al. Anatomic considerations for the placement of C2 laminar screws. Spine 2006;:2767-2771.

59. Wright NM. Posterior C2 fixation using bilateral, crossing $\mathrm{C} 2$ laminar screws: case series and technical note. Clin Spine Surg 2004;17:158-62.

60. Harms J, Melcher RP. Posterior C1-C2 fusion with polyaxial screw and rod fixation. Spine 2001;26:2467-71.

61. Guo X, Ni B, Zhao W, et al. Biomechanical assessment of bilateral C1 laminar hook and C1-2 transarticular screws and bone graft for atlantoaxial instability. Clin Spine Surg 2009;22:578-85.

62. Haid Jr RW, Subach BR, McLaughlin $\mathrm{MR}$, et al. $\mathrm{C} 1-\mathrm{C} 2$ transarticular screw fixation for atlantoaxial instability: a 6year experience. Neurosurgery 2001;49:65-70.

63. Finn MA, Apfelbaum RI. Atlantoaxial transarticular screw fixation: update on technique and outcomes in 269 patients. Neurosurgery 2010;6:A184-92.

64. Platzer P, Vécsei V, Thalhammer G, et al. Posterior atlanto-axial arthrodesis for fixation of odontoid nonunions. Spine 2008;33:624-30.

65. Haid Jr RW. C1-C2 transarticular screw fixation: technical aspects. Neurosurgery 2001;49:71-4.

66. McGuire RA, Harkey HL. Modification of technique and results of atlantoaxial transfacet stabilization. Orthopedics 1995;18:1029-32.

67. Goel A, Laheri V. Plate and screw fixation for atlanto-axial subluxation. Acta Neurochir 1994;129:47-53.

68. Abumi K, Itoh H, Taneichi H, Kaneda K. Transpedicular screw fixation for traumatic lesions of the middle and lower cervical spine: description of the techniques and preliminary report. Clin Spine Surg 1994;7:19-28.

69. Deen HG, Birch BD, Wharen RE, Reimer R. Lateral mass screw-rod fixation of the cervical spine: a prospective clinical series with 1-year follow-up. Spine J 2003;3:489-95.

70. De Iure F, Donthineni R, Boriani S. Outcomes of $\mathrm{C} 1$ and $\mathrm{C} 2$ posterior screw fixation for upper cervical spine fusion. Eur Spine J 2009;18:2. 